\title{
Seedling Production from Seeds of a Wild Ecotype of Vetiver Grass (Vetiveria zizanioides L.) in Southern China
}

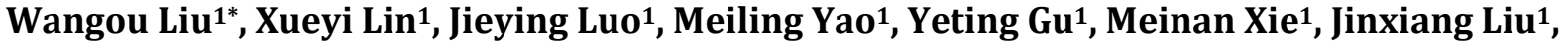 \\ Qifu Ma'
}

${ }^{1}$ Life Science and Technology School, Lingnan Normal University, Zhanjiang, China

${ }^{2}$ School of Veterinary and Life Sciences, Murdoch University, Murdoch, Australia

Email: *liuwangou@163.com

How to cite this paper: Liu, W.G., Lin, X.Y., Luo, J.Y., Yao, M.L., Gu, Y.T., Xie, M.N., Liu, J.X. and Ma, Q.F. (2021) Seedling Production from Seeds of a Wild Ecotype of Vetiver Grass (Vetiveria zizanioides L.) in Southern China. American Journal of Plant Sciences, 12, 394-405.

https://doi.org/10.4236/ajps.2021.123025

Received: February 10, 2021

Accepted: March 27, 2021

Published: March 30, 2021

Copyright $\odot 2021$ by author(s) and Scientific Research Publishing Inc. This work is licensed under the Creative Commons Attribution International License (CC BY 4.0).

http://creativecommons.org/licenses/by/4.0/

(c) (i) Open Access

\begin{abstract}
Vetiver grass (Vetiveria zizanioides L.) is widely used for soil and water conservation, and land management. In practice, all vetiver seedlings are propagated via ramets or tillers, which cannot meet the market demand and would also destroy the original habitat. Most vetiver genotypes flower but do not produce seeds. A wild ecotype of vetiver grass originated in southern China is fertile, but the rate of seed germination is very low. This study aimed to develop a novel method to improve its seed germination and seedling establishment. In the field, the inflorescences of wild vetiver were wrapped using a transparent plastic bag with a pot containing wet soils. The effects of inflorescence bagging and Tween 80 application on seed germination and seedling growth were examined. The results showed that seed development was characterized by low seed setting rate (19.2\%), uneven maturity time, easy shedding (more than $95 \%$ of spikelets shed off 20 days after flowering), therefore difficult harvest of viable seeds. Bagging the inflorescence with moist soils in pot ensured the mature seeds falling onto the nursery soil surface and absorbing water for germination while the immature seeds continued to grow on the inflorescence. Bigging not only improved seed development and maturity, saved the procedure of seed collection and storage, but also provided a humid micro-environment for seed germination and seedling growth. Tween 80 as a surfactant promoted seed water absorption, germination and seedling growth. This simple and novel method has integrated the procedures of seed collection, storage, germination and seedling establishment, and enables the production of a large number of healthy seedlings. The possible reasons for the degeneration and disappearance of the original population were also discussed from the perspective of the disadvantages of vetiver propagation.
\end{abstract}




\section{Keywords}

Wild Vetiver ( Vetiveria zizanioides L.), Seed-Born Seedling, Bagging, Tween 80, Population Degeneration

\section{Introduction}

Vetiver grass (Vetiveria zizanioides L.) is a perennial herbaceous plant of the genus Vetiver of Gramineae, and has the characteristics of strong adaptability, fast growth, well-developed reticular root system, drought resistance and barren tolerance etc. It is regarded as an ideal plant species for soil and water conservation by more than 120 countries and regions [1] [2], playing an important role in restoration of degraded landscape, bioremediation of soils contaminated with heavy metals and pollutants [3] [4]. It is reported that nearly $1 / 3$ of China's land area suffers different degrees of soil and water loss, and urgently requires the situation under control by growing vetiver grasses [5]. However, all vetiver grasses currently in use are propagated by the method of splitting growing plants and transplanting the slips, which is not only unable to meet the market demand but can also destroy the original habitat [6]. Moreover, tissue culture of vetiver grass has been carried out [7] [8] [9], but is not feasible for high-quantity production.

There have been few reports on the seed-born seedling of vetiver because of low germination rate. Parihar et al. [10] reported that an ecotypic vetiver in India had seed germination of $18.5 \%$. In contrast, the germination rate of the vetiver seeds from southern China was only $0.5 \%$ and reached $14.0 \%$ after gibberellin treatment, and the survival rate of seedlings was about $50 \%$ after transplanting [11]. The highest germination rate was $9.5 \%$ when the seeds were treated with variable temperatures $\left(25^{\circ} \mathrm{C}-35^{\circ} \mathrm{C}\right)$ [12]. The present seed germination methods require seed collection and storage, which can be problematic for vetiver seeds. Because of the inconsistent seed maturation in the vetiver inflorescences and the tendency of falling off while maturing [11], viable seeds are often difficult to collect, and partially account for low germination of the vetiver seeds. In addition, these methods need hormone treatment [11], growth chamber to control temperature [12], transplanting to nursery after germination etc., leading to low survival rate and hence limitation for field application.

There are flowering and non-flowering vetiver plants [13]. Most vetiver genotypes flower but do not produce seeds. In Wuchuan County $\left(21^{\circ} 30^{\prime} \mathrm{N}, 110^{\circ} 50^{\prime} \mathrm{E}\right)$, Guangdong Province of China, a wild and fertile ecotype of vetiver grass was found in May, 1957 [14]. This vetiver community extended over an area of about 6700 ha in the 1950's, but has now completely disappeared in the wild. Fortunately, the germplasm of this species was introduced into the Grass Research Station of Lingnan Normal University in 2002 [15]. After more than 18 years of cultivation, we found that the seeds (or spikelets) of this ecotypic vetiver rarely germinated in the field (Figure 1(u)), indicating that it is very difficult to pro- 
duce seedlings from vetiver seeds under natural conditions.

Seed-born seedlings can not only alleviate the shortage of seedlings due to merely asexual reproduction method, but also avoid the destruction of vetiver habitat by ramet excavation and thus protect the germplasm resources. The aim of this research was to develop a new method for promoting seed germination and seedling production of a wild vetiver. The degeneration of the original population was also discussed according to the characteristics of seed germination.
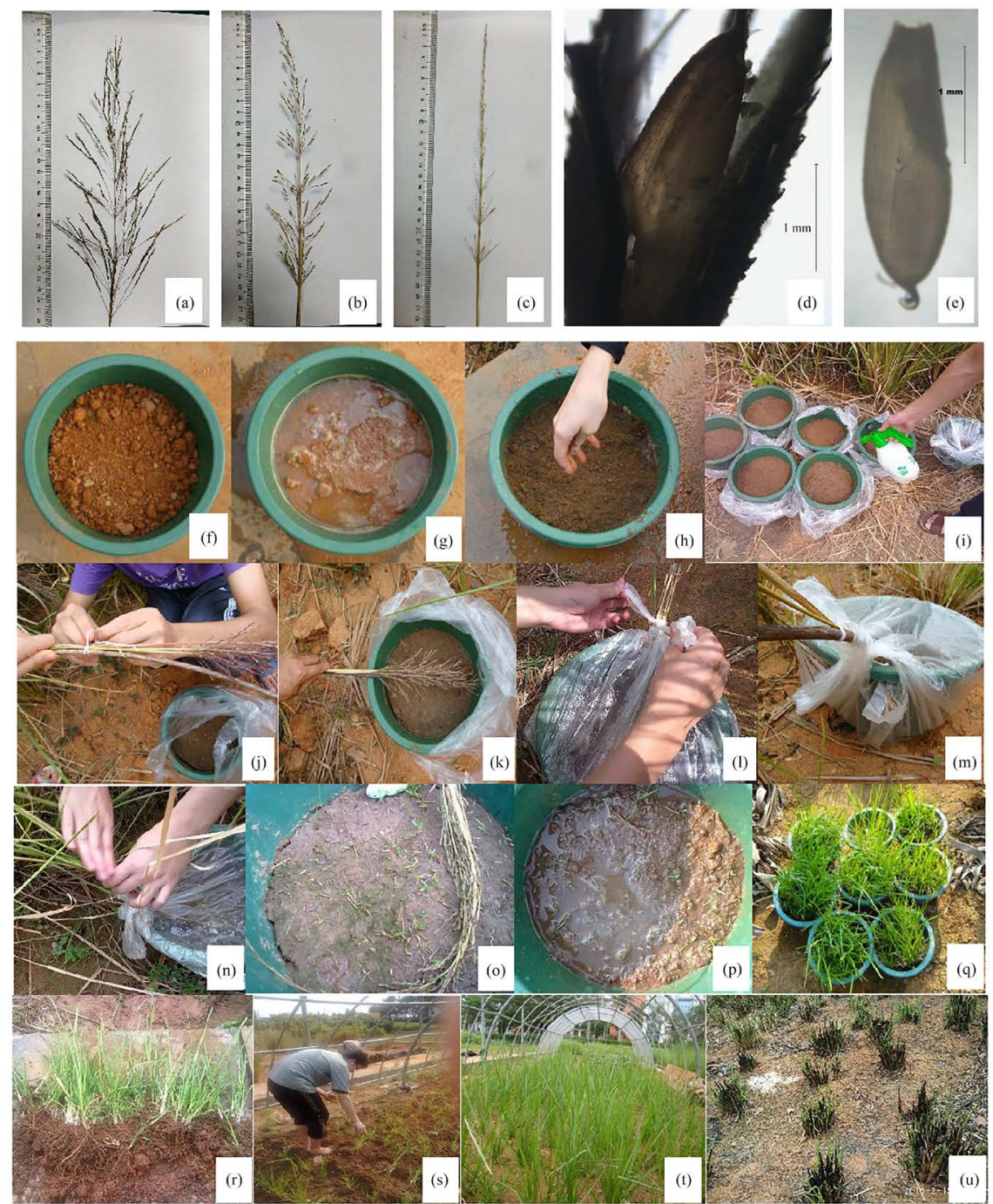

Figure 1. Inflorescence of wild vetiver and the process of seedling production from seeds. (a) Flowering inflorescence; (b) Inflorescence with some spikelets fell; (c) Inflorescence without spikelets; (d) Caryopsis packed in husks; (e) Caryopsis (seed); (f) Pot with coarse soil; (g) Water to saturation; (h) Cover with fine soil; (i) Spraying $0.5 \%$ Tween 80 solution; (j) Fix inflorescence on the rod; (k) Bending the inflorescence; (l) Tie the bag; (m) Keep a hole in side of the bag; (n) Vibrate the stem to shed the spikelets; (o) Remove the bag and germination occurred 20 days after bagging; ( $p$ ) Covered with fine soil and water; (q) Seedlings 150 days after bagging; (r) Seedlings; (s) Transplant seedlings in field; (t) Vetiver grass 40 days after planting; (u) No seed-born vetiver plants were found between the rows 15 years after establishment of vetiver turf. 


\section{Material and Method}

\subsection{Plant Material and Experimental Site}

The germplasm of the wild ecotype of vetiver [16] was introduced into the Grass Research Station of Lingnan Normal University, Zhanjiang, South Chian's Guangdong province $\left(20^{\circ} 55^{\prime} \mathrm{N}, 110^{\circ} 11^{\prime} \mathrm{E}\right)$ from Wuchuan County $\left(21^{\circ} 30^{\prime} \mathrm{N}\right.$, $110^{\circ} 50^{\prime} \mathrm{E}$ ) in 2002 [15] [17], and the experiment was carried out on 13 September 2015. The average annual rainfall, annual relative humidity (RH) and annual temperature are $1731.4 \mathrm{~mm}, 80 \%$ and $23.5^{\circ} \mathrm{C}$, respectively at the experimental site. In particular, the average monthly rainfall is $231.4 \mathrm{~mm}, 80 \% \mathrm{RH}$ and temperature $27.6^{\circ} \mathrm{C}$ in September.

\subsection{Pot Preparation}

The field topsoil was collected from the Grass Research Station of Lingnan Normal University and 60 plastic pots were used in the nursery. The sandy loam with soil $\mathrm{pH}$ of 5.8 contained organic matter of $24.1 \mathrm{~g} \cdot \mathrm{kg}^{-1}$, total $\mathrm{N}$ of $1.18 \mathrm{~g} \cdot \mathrm{kg}^{-1}$, available $\mathrm{N}$ of $93.48 \mathrm{mg} \cdot \mathrm{kg}^{-1}$, available $\mathrm{P}$ of $89.7 \mathrm{mg} \cdot \mathrm{kg}^{-1}$, and available $\mathrm{K}$ of 78.8 $\mathrm{mg} \cdot \mathrm{kg}^{-1}$. The pots were $18 \mathrm{~cm}$ high, $25 \mathrm{~cm}$ in diameter containing $7 \mathrm{~kg}$ of soil (Figure 1(f)). After watering to saturation (Figure 1(g)), the soil surfaces were covered with a thickness of about $0.5 \mathrm{~cm}$ of fine soil (passed through a $2-\mathrm{mm}$ sieve) for preventing seeds from falling into deep soil through large soil pores (Figure $1(\mathrm{~h})$ ). Of all the 60 pots, 50 pots were sprayed with $100 \mathrm{~mL}$ of $0.5 \%$ Tween 80 aqueous solution (volume ratio) [18] on the soil surface and 10 pots with $100 \mathrm{~mL}$ distilled water as control. The pots were then packaged with transparent plastic bags to prevent water evaporation from soil surface and placed between the rows of vetiver grass in the field (Figure 1(i)).

\subsection{Bagging Experiment}

In the field, 60 uniform vetiver inflorescences with basal seeds beginning to mature (purple spikelets turn into light brown), main stem height about $2 \mathrm{~m}$ and panicle length about $25 \mathrm{~cm}$ were selected. Two inflorescences were selected in each pot at random and bent the main stem (the main stem is soft and elastic). The plastic bag was opened at a $45^{\circ}$ angle with the mouth facing upward. The bases of the inflorescences were fixed on a rod (plant branches, about $1 \mathrm{~cm}$ in diameter and about $30 \mathrm{~cm}$ in length) with a packing rope (Figure $1(j)$ ). The position of the pot and the plastic bag was adjusted to ensure the curved inflorescence was over the pot and the bag. One end of the rod was inserted into the soil in the pot (Figure 1(k)) and two handles of the plastic bag were tied the reverse around the other end so that the inflorescence is fixed in the pot, i.e. the pot and inflorescence were wrapped together in the plastic bag (Figure 1(1)). An aperture of about $2 \mathrm{~cm}$ was left on the side of the bag to allow ventilation (Figure $1(\mathrm{~m})) .10$ pots sprayed with Tween 80 and distilled water were packed in plastic bag, respectively, and 10 pots sprayed with Tween 80 left without bagging. Tap- 
ping the main stem with a pole or hand every five days to produce vibrations will facilitate the seeds or spikelets to shed off and evenly scatter on the soil surface in the pot (Figure 1(n)). The temperature and relative humidity inside and outside the bags were monitored with thermometer and humidometer, respectively. The inflorescences and plastic bags were removed 20 days after the bagging (Figure 1(o)). After counting the number of seed germination, the soil surface was covered with a thickness of about $2 \mathrm{~mm}$ of fine soil and watered (Figure $1(\mathrm{p})$ ). After 150 days (Figure 1(o)), the seedlings were removed from the soil (Figure 1(r)) and the number of seedlings per pot was recorded. Ten seedlings randomly selected from each pot, were washed carefully with tap water to remove debris and the plant fresh weight and height were determined after excess water was sucked by suction paper. The remaining seedlings were transplanted to the field (Figure 1(s), Figure 1(t)).

\subsection{Germination Rate of Maturing Seeds over Times}

In the field, 60 uniform vetiver inflorescences with the basal seeds beginning to mature, the main stem about $2 \mathrm{~m}$ high and the panicle about $25 \mathrm{~cm}$ long were selected. All seeds (spikelets) on 20 inflorescences were collected separately at day 0 , day 10 and day 20 after the beginning of bagging experiment. The seeds (spikelets) from 2 inflorescences were sowed evenly on the soil surface in one pot which was sprayed with $0.5 \%$ Tween solution, for a total of 30 pots. The pots were arranged between the vetiver rows and wrapped in the plastic bag with an aperture of about $2 \mathrm{~cm}$ on the side of the bag for ventilation. The germination number was measured at 20 days after sowing.

\subsection{Measurement of Seed Setting Rate}

At the beginning of the bagging experiment, an inflorescence was bagged using a white air-permeable non-woven bag to prevent seeds or spikelets from falling when maturing, and a total of 10 inflorescences were bagged. Twenty days later, the number of spikelets (shed and intact), sterile spikelets and seeds in the inflorescences were counted under a dissecting microscope $(6 \times 40$ magnification, Olympus SZX7, Japan).

\subsection{Statistical Analysis}

1) Spikelet number $=$ fertile spikelet number $(=$ seed number $)+$ sterile spikelet number

2) Seed setting rate $=($ seed number/spikelet number $) \times 100 \%$

3) Sterile spikelet rate $=100 \%$ - Seed setting rate

4) Germination rate $=$ (germination number/seed number) $\times 100 \%$

5) Seedling rate $=$ (number of seedlings/germinating number $) \times 100 \%$

Data were examined by one-way analysis of variance using SPSS18.0 for Windows (SPSS Inc., Chicago, IL, USA) and differences between means ( $p<$ 0.05 ) were assessed by Duncan's multiple range test. 


\section{Results}

\subsection{Climatic Conditions during the Experiment}

During the experiment (20 days), the average temperature was $26.4^{\circ} \mathrm{C}$, with total rainfall $53.5 \mathrm{~mm}$, average $\mathrm{RH} 72.8 \%$, total evaporation $97 \mathrm{~mm}$, average sunshine hours $7.78 \mathrm{~h}$, and average wind speed $2.56 \mathrm{~m} / \mathrm{s}$. The temperature is $24.6^{\circ} \mathrm{C}$ $38.5^{\circ} \mathrm{C}$ inside the bag and $21.2^{\circ} \mathrm{C}-33.6^{\circ} \mathrm{C}$ outside. $\mathrm{RH}$ is $100 \%$ inside the bag and $37 \%-88 \%$ outside.

\subsection{Seed Setting Rate of the Wild Vetiver}

The inflorescence of wild vetiver grass produced a large number of spikelets, but only 159 seeds per inflorescence and $17.9 \%$ of seed-setting rate (Table 1), indicating the vast majority of spikelets are sterile $(82.1 \%)$. In addition, more than $95 \%$ of spikelets shed off the inflorescence 20 days after basal seed began to mature, suggesting that seeds or spikelets tend to fall off after maturing.

\subsection{Effects of Bagging and Tween 80 Treatment on Seed Germination Rate, Seedling Rate and Seedling Growth of Vetiver}

The germination rate of non-bagging treatment is nil, whereas bagging significantly increased the germination rate (Table 2). In addition, under bagging, compared with water treatment, $0.5 \%$ Tween 80 treatment significantly increased seed germination rate, seedling rate, plant height as well as plant fresh weight by $22.8 \%, 9.1 \%, 15.3 \%$ and $29.3 \%$, respectively.

\subsection{Effect of Harvest Times on Seed Germination Rate}

The germination rates of the seeds collected on 0 day, 10 days and 20 days, respectively, after the beginning of bagging experiment are significantly different (Table 3). The germination rate of seeds harvested at day 10 was the highest, with day 20 the lowest. The germination rates of seeds harvested on the day 0,10 and 20 decreased by $90.2 \%, 73.4 \%$ and $98.3 \%$, respectively, compared with $0.5 \%$ Tween + bagging (Table 2).

Table 1. Seed setting percent of vetiver grass in southern China.

\begin{tabular}{ccccc}
\hline Spikelets (No/head) & Shed spikelets (No/head) & Seeds (No/head) & Seed-setting rate (\%) & Sterile spikelet rate (\%) \\
\hline $889.0 \pm 32.05$ & $848.1 \pm 28.17$ & $159.4 \pm 11.53$ & $17.9 \pm 0.72$ & $82.1 \pm 0.72$ \\
\hline
\end{tabular}

Means \pm SD. $(\mathrm{n}=10)$.

Table 2. Germination rate, seedling rate and seedling growth of vetiver grass under different treatments.

\begin{tabular}{|c|c|c|c|c|c|c|}
\hline Treatments & $\begin{array}{l}\text { Germination number } \\
\text { (No/pot) }\end{array}$ & $\begin{array}{c}\text { Germination rate } \\
(\%)\end{array}$ & $\begin{array}{l}\text { Seedling number } \\
\text { (No/pot) }\end{array}$ & $\begin{array}{l}\text { Seedling rate } \\
(\%)\end{array}$ & $\begin{array}{l}\text { Seedling height } \\
(\mathrm{cm})\end{array}$ & $\begin{array}{c}\text { Fresh weight } \\
\text { (g/plant) }\end{array}$ \\
\hline $0.5 \%$ Tween 80 & $0^{\mathrm{a}}$ & $0^{\mathrm{a}}$ & $0^{\mathrm{a}}$ & $0^{\mathrm{a}}$ & $0^{\mathrm{a}}$ & $0^{\mathrm{a}}$ \\
\hline Water + bagging & $92.1 \pm 5.74^{\mathrm{b}}$ & $29.0 \pm 1.81^{\mathrm{b}}$ & $74.1 \pm 5.43^{\mathrm{b}}$ & $80.4 \pm 2.19^{b}$ & $36.5 \pm 2.17^{\mathrm{b}}$ & $4.1 \pm 0.19^{\mathrm{b}}$ \\
\hline $0.5 \%$ Tween $80+$ bagging & $113.1 \pm 12.49^{c}$ & $35.6 \pm 3.93^{c}$ & $99.1 \pm 11.12^{c}$ & $87.7 \pm 3.16^{\mathrm{c}}$ & $42.1 \pm 3.14^{\mathrm{c}}$ & $5.3 \pm 0.19^{c}$ \\
\hline
\end{tabular}

Different letters in the same column show significant difference between treatments $(P<0.05)$, means \pm SD $(\mathrm{n}=10)$. 
Table 3. Effect of seed collection times on seed germination of vetiver grass. Day 0 refers to the time when the basal seeds begin to mature (purple spikelets turn into light brown).

\begin{tabular}{ccc}
\hline $\begin{array}{c}\text { Days of seed collection } \\
\text { (day) }\end{array}$ & $\begin{array}{c}\text { Germination number } \\
(\text { No/pot })\end{array}$ & \multicolumn{2}{c}{ Germination rate } \\
$(\%)$
\end{tabular}

Different letters in the same column show significant difference among treatments $(P<0.05)$, Means \pm SD $(n=10)$.

\section{Discussion}

\subsection{Fruiting Characteristics of the Wild Vetiver}

Under the dissecting microscope, it was clear that this wild vetiver possesses two kinds of spikelets occurring in pairs on a loose many-branched seed heads (Figure 1(a)). One of each pair is pedicelled spikelet which always staminate and sterile, while the other one is sessile spikelet with potential fertility but often abortion. This could explain why the seed-setting rate was so low though a large number of spikelets occurred in each inflorescence (Table 1), which was consistent with previous reports [10] [19]. In an individual inflorescence, flowering could last for about 10 days, and spikelets started to shed off 15 - 20 days after flowering (Figure 1(b)) and the shedding process would last for 20 days (Figure $1(c)$ ). The fact of uneven ripening of seeds and easy shattering of spikelets in an individual inflorescence of the wild vetiver made it difficult to collect large amount of mature seeds manually, and the maturing seeds collected over time had different germination rates (Table 3). For each inflorescence, only a small number of newly ripe seeds and immature seeds can be collected because of the tendency of shedding of mature seeds. If the collection was too early, a high proportion of immature seeds would be obtained, otherwise only a small number of mature seeds could be collected due to the shedding of mature seeds.

\subsection{Bagging and Seed Germination Rate}

Under no bagging, the seed germination rate of the wild vetiver was nil. In contrast, bagging significantly increased the germination rate (Table 2), much higher than that of the previous reports [11] [12]. It was likely that bagging could prevent seed from dehydration as $100 \% \mathrm{RH}$ was recorded inside the bags during the experiment. It was reported that the germination rate of one wild-type vetiver was $70 \%$ when the seeds were harvested before the shedding of spikelets, but dropped dramatically to $40 \%$ and $10 \%$, respectively when seeds were left for 3 and 7 days due to dehydration [20]. Bagging also keeps the soil surface in the state of moisture which would promote the water absorption of seeds and spikelets instantly. It is well known that seeds of tropical plants usually have a short life span, and that the seeds of vetiver, a typical tropical plant, will readily lost their viability during the storage [12]. The seeds of the wild vetiver in south China mature during the dry season from September to November, with 
average monthly rainfall of $103.4,87.0$ and $45.4 \mathrm{~mm}$ in September, October and November, respectively. In addition, the caryopsis are usually still enclosed in husks after the spikelets shed off (Figure 1(d)), which would prevent water absorption for seeds from surroundings. If spikelets fall on the dry soil, it is easy for ripe seeds to lose vigor due to dehydration. In the present study, wrapping the pots with impermeable plastic bag (Figure 1(1)) could not only reduce water evaporation from soil surface in the pot but also prevent water vapor from escaping the bag, which would create a high humidity microenvironment for vetiver seeds, so as to prevent the seeds from reducing vitality due to dehydration and promote germination rate. Secondly, transparent plastic bags which would secure sufficient light intensity inside the bags and an aperture in the bag (Figure $1(\mathrm{~m})$ ) for influx of oxgen and efflux of $\mathrm{CO}_{2}$ could minimize the negative impact of bagging on the growth and development of the inflorescences, therefore the seeds can grow and develop healthily inside the bag. When seeds were ripe and spikelets shed, the moist environment will synchronize the process of shedding and water absorption of seeds (or spikelets). Thirdly, originated in tropical and subtropical regions, vetiver requires high temperature for seed germination. Bagging increased the micro-environmental temperature $\left(24.6^{\circ} \mathrm{C}\right.$ $38.5^{\circ} \mathrm{C}$ inside vs $21.2^{\circ} \mathrm{C}-33.6^{\circ} \mathrm{C}$ outside), and promoted seed germination.

\subsection{Tween 80 and Seed Germination}

According to Parihar et al. [10], vetiver seeds have a postmature dormancy of about three months, while others reported no dormancy period [21], or even a decrease in seed germination after storage for just few days [20]. Our study was consistent with the latter, i.e. vetiver seeds can germinate immediately after maturity (Figure 1(0)). Sometimes, we even observed that spikelets germinated on the inflorescences without shedding. Our results likely indicate the dormancy of vetiver seed is largely due to mechanical inhibitor other than physiological factor because dehusking the spikelets could significantly increase the germination rate of vetiver seeds, for husks may impose mechanical restraint or restrict the availability of oxygen to the embryo [22]. After the shedding of spikelet, the seeds (caryopses) of the vetiver were still enclosed in the husks (Figure 1(d)) that covered with hydrophobic substances such as wax and epidermal hairs, preventing the absorption of water for seeds from the circumstances. Tween 80 , an emulsifier, as a surfactant interacting with membrane proteins which made them more hydrophilic can reduce surface tension of both husks and seed coats and facilitate water absorption, therefore, promote seed germination rate [18] [23]. Meanwhile, Tween 80 has the ability to improve the level of endogenous IAA [18], which also promotes seed germination. Among other things, antimicrobial activity of the emulsifier Tween 80 [24] also contributes to promotion of seed germination rate, for the moldy seeds were often observed in culture dishes [12] as did in our experiment without application of Tween 80 .

Our result also showed that Tween 80 can significantly promote the growth of vetiver seedlings (Table 2), largely attributed to the fact that Tween 80 can pro- 
mote water absorption of seeds and earlier germination, and extend the seedling growth period. In addition, Tween 80 could also increase endogenous IAA level in seedlings and promote seedling growth [18].

\subsection{Bagging Improves Seedling Survival}

In this experiment, the seedling rate of vetiver was more than $80 \%$ (Table 2), much higher than that of the previous report [11]. Owing to the very tiny seeds (Figure 1(o)), very thin and weak as the newborn vetiver seedlings are (Figure $1(\mathrm{e})$ ), the delicate seedlings are vulnerable to mechanical damage in the process of transplantation and environmental stresses e.g. drought, therefore seedling rates were often very low [11]. In this study, both seed germination and seedling culture were carried out in the same pot (Figure 1(o)), which would eliminate the adverse factors caused by transplanting, therefore improve the seedling rate.

\subsection{Possible Causes of Natural Population Degradation of the Wild Vetiver}

The original community of the vetiver was located on the river alluvial plain in the lower reaches of the Jianjiang river in western Guangdong province, China with several tributaries running through it. In 1957, the total area of the community was 6700 ha [14]. Although other populations were distributed in the community, such as Herba chinensis, Sweet Leymus, etc., vetiver was the dominant species. By 1997, however, the community had been completely fragmented, and the area had shrunk significantly with vetiver grass only being distributed in low-lying flooded areas and seasonally flooded areas. By 2002, the area of the population was reduced to less than 150 ha [15] and completely disappeared in 2013. In less than 60 years, such a large area of the population has disappeared, though human activities, such as land reclamation and land clearing, have an unshirkable responsibility, its own reproductive disadvantage cannot be ignored. First, it is difficult for vetiver grass to reproduce asexually under natural conditions. It is reported that mowing vetiver grass twice a year can promote tillering and growth of vetiver, while the absence of mowing could inhibit tillering and the cluster will inevitably die [25] [26]. A similar case was observed in our grass research station, where burning practice could promote tillering more than shearing (Figure 1(u)). Before the 20th century, vetiver was cut frequently to meet people's needs for fuel and materials for building huts, inadvertently helping to breed vetiver. With the advent of China's reform and opening up in the late 1970s, the use of fossil fuels and modern building materials has sharply reduced the demand for vetiver. Therefore, the cutting amount of vetiver is reduced, which exacerbated the degradation of vetiver. Secondly, it is difficult to reproduce vetiver sexually under natural conditions. This vetiver grass is a wetland one [27]. The results mentioned above showed that the seeds can only germinate under high humidity. In the early years, the land of habitat was flat, with many rivers and rivers, forming a dense river network. During the flood period from April to September, seasonal wetlands were formed [14]. Mature 
seeds fall onto wet soil and absorb water to germinate. However, in 1990s, as the result of canals and fish ponds were built, which caused water levels drop and wetlands disappear, the fallen seeds could not germinate because of drought. In conclusion, the degeneration and disappearance of this vetiver population in south China is caused by the combination of human activities and its own reproductive disadvantage, which also determines its character of non-invasive weed [27] [28]. This is just our opinion, and if there is anything incorrect, please criticize and correct.

\section{Conclusion}

In conclusion, because of the inconsistency of seed maturity of wild vetiver in south China, it is not easy to collect mature seeds manually, and the seeds are easy to be dehydrated and lose vigor after ripening, which leads to difficult germination under natural conditions. Bagging the inflorescences and a pot containing wet soils using a transparent plastic bag provides a transparent, high-humidity microenvironment for seeds, which prevents seeds from dehydration and reduction of vigor, and promotes seed germination by facilitating water uptake. Tween 80 can not only reduce the surface tension of seeds, facilitating more rapid water absorption and seed germination, but also promote the growth of seedlings. The mentioned method integrates seed growth, maturation, collection, storage, germination and seedling raising, which warrant high seed germination rate and strong seedlings. The inferiority of wild vetiver propagation in south China is one of the reasons that cause the origin population to degenerate and disappear.

\section{Acknowledgements}

This work was supported by grant from Guangdong Provincial Teaching Quality Engineering Project (2020, the Building of Landscape Architecture Specialty).

\section{Conflicts of Interest}

The authors declare no conflicts of interest regarding the publication of this paper.

\section{References}

[1] Donjadee, S. and Tingsanchali, T. (2012) Reduction of Runoff and Soil Loss over Steep Slopes by Using Vetiver Hedgerow Systems. Paddy and Water Environment, 11, 573-581. https://doi.org/10.1007/s10333-012-0350-2

[2] Truong, P. and Loch, R. (2004) Vetiver System for Erosion and Sediment Control. Proceedings of the 13th International Soil Conservation Organisation Conference, Brisbane, July 2004, 1-6.

[3] Truong, P.N.V. (1994) Vetiver Grass, Its Potential in the Stabilisation and Rehabilitation of Degraded Saline Land. In: Squires, V.R. and Ayoub, A.T., Eds., Halophytes as a Resource for Livestock and for Rehabilitation of Degraded Lands, Vol. 32, Kluwer Academic Publishers, Dordrecht, 293-296.

https://doi.org/10.1007/978-94-011-0818-8 31 
[4] Truong, P., Van, T.T. and Pinners, E. (2008) Vetiver System Applications Technical Reference Manual. 2nd Edition, The Vetiver Network International, 78-89.

[5] Tian, W.T., Hu, W.Y., Li, J. and Gao, Z.L. (2008) The Status of Soil and Water Loss and Analysis of Countermeasures in China. Research of Soil and Water Conservation, 15, 204-209. (In Chinese)

[6] Ma, P., Yang, H. and Ma, X.R. (2011) Progress in Research and Utilization of Vetiveriazi Zanioides. Journal of Agricultural Science and Technology, 13, 88-93. (In Chinese)

[7] Yang, B.B., P, X.H. and Ma, Z.R. (2007) Study on Tissue Culture of Vetiver Grass. Acta Prataculturae Sinica, 16, 93-99. (In Chinese)

[8] Prasertsongskun, S. (2004) Isolation and Culture of Suspension Protoplasts of Vetiver. Songklanakarin Journal of Science and Technology, 26, 411-416.

[9] Wang, D., Cao, Y.N., Ma, L., Chen, X.W., Zhang, F. and Chen, J.B. (2019) Study on Seedling Regeneration from Axillary Buds of Stem Nodes of Vetiveria zizanioides in Vitro. Molecular Plant Breeding, 17, 1313-1319. (In Chinese)

[10] Parihar, S., Mal, B., Shankar, V. and Kak, A. (1998) Seed Production and Germination in Vetiver Grass (Vetiveria zizanioides). Tropical Grasslands, 32, 173-177. (In Chinese)

[11] Liu, J.X., Zhang, Y. and Li, X.D. (2012) Effect of GA3 Treatments on Seed Germination Dynamics of Natural Vetiver Grass in Western Guangdong Province. Chinese Journal of Tropical Crops, 33, 1272-1275. (In Chinese)

[12] Yao, C., Zhu, G.C. and Liu, H. (2007) Study on Reproduction from Seed Born Seedling of Vetiver Grass. Journal of Yangtze University (Nat Sci Edit), 4, 13-15, 26. (In Chinese)

[13] Leupin, R.E., Leupin, M., Ehret, C., Erismann, K.H. and Witholt, B. (2000) Compact Callus Induction and Plant Regeneration of a Non-Flowering Vetiver from Java. Plant Cell, Tissue and Organ Culture, 62, 115-123. https://doi.org/10.1023/A:1026589500827

[14] Xia, H.P. and Ao, D.X. (1998) Wild Vetiver Grass Distributed in China and Its Protection and Taxonomic Problems. Biodiversity conservation in China, 6, 292-297. (In Chinese)

[15] Liu, J.X. and Chen, Y. (2002) Issues of Utilization and Protection for Native Vetiver Grass. Pratacultural Science, 19, 13-16. (In Chinese)

[16] Xia, H.P. and Liu, S.Z. (2003) Study on Screening for Excellent Ecotypes of Vetiveria Zizanioides. Acta Prataculturae Sinica, 12, 97-105. (In Chinese)

[17] Liu, W.G., Liu, J.X., Yao, M.L. and Ma, Q.F. (2016) Salt Tolerance of a Wild Ecotype of Vetiver Grass (Vetiveria zizanioides L.) in Southern China. Botanical Studies, 57, Article No. 27. https://doi.org/10.1186/s40529-016-0142-X

[18] Zhong, H.X., Dong, H., Zhou, J.H. and Liang, H.M. (1993) Effects of Tween-80 on the Germination and Some Physiological and Biochemical Characters of Barley Seeds. Acta Agrinomica Sinica, 19, 376-379. (In Chinese)

[19] Liu, J.X., Li, W.S. and Li, H.Y. (2005) A Primary Report on Biological Characteristics and Insect Pest of Seeding Reproductive Vetiver Grass. Pratacultural Science, 22 108-111. (In Chinese)

[20] Office of the Royal Development Projects (BOARD) (2000) Manual of the International Training Course on the Vetiver System. Organized by the Office of the Royal Development Projects Board in Cooperation with the Chaipattana Foundation with Fund Donated by the Heineken Breweries Co. Ltd., Bangkok, Thailand, 19-30 No- 
vember 2000 .

[21] Moula, G. and Rahman, S. (2009) Seed Germination Potential of Vetiver Grass (Vetiveria zizanioides L. Nash). Pakistan Journal of Agricultural Research, 22, 97-100.

[22] Simpson, G.M. (2007) Seed Dormancy in Grasses. Cambridge University Press, Cambridge.

[23] Dunaeva, M., Bocharova, M., Aksenova, L. and Klyachko, N. (1991) Effect of Tween-80 on Moisture-Content of Germinating Wheat Seeds. Soviet Plant Physiology, 38, 115-120.

[24] Lucie, L.A., Stéphanie, G., Fabienne, C., Olivier, C., François, L.J., Corinne, R.M., Noémie, D., Gabrielle, M.A., Ivan, L., Louis, C. and Nicolas, D. (2018) Dispersed Phase Volume Fraction, Weak Acids and Tween 80 in a Model Emulsion: Effect on the Germination and Growth of Bacillus Weihenstephanensis KBAB4 Spores. Food Research International, 109, 288-297. https://doi.org/10.1016/j.foodres.2018.04.016

[25] Liu, J.G. and Xue, J.H. (2009) Effects of Cutting on Early-Stage Plant Community Characteristics of Slope Land Protected by Vetiveria zizanioides (L.). Acta Agrestia Sinica, 17, 520-526. (In Chinese)

[26] Liu, J.G., Liu, H.X., Chen, W.P., Gao, W.L. and Bian, X.M. (2007) Impacts of Clipping on the Growth of Vetiveria zizanioides. Grassland and Turf, No. 4, 82-86. (In Chinese)

[27] Xia, H.P., Wang, M.Z. and Xu, L.Y. (2015) Is Vetiver Grass Planted in China an Invasive Alien Species and Becoming a Weed? Chinese Journal of Ecology, 34, 2327-2332. (In Chinese)

[28] Li, Z.Y. and Xie, Y. (2002) Invasive Alien Species in China. China Forestry Press, Beijing. 